\title{
Liquid permeation and chemical stability of anodic alumina membranes
}

\author{
Dmitrii I. Petukhov ${ }^{* 1,2}$, Dmitrii A. Buldakov², Alexey A. Tishkin ${ }^{2}$, Alexey V. Lukashin ${ }^{1,2}$ \\ and Andrei A. Eliseev ${ }^{1,2}$
}

\author{
Full Research Paper \\ Address: \\ ${ }^{1}$ Department of Chemistry, Lomonosov Moscow State University, \\ Moscow 119991 Leninskie hills 1-3, Russia and ${ }^{2}$ Department of \\ Materials Science, Lomonosov Moscow State University, Moscow \\ 119991 Leninskie hills, Russia \\ Email: \\ Dmitrii I. Petukhov* - di.petukhov@gmail.com \\ * Corresponding author \\ Keywords: \\ anodic alumina; carbon-modified membranes; membrane stability; \\ microfiltration membranes; ultrafiltration membranes \\ Beilstein J. Nanotechnol. 2017, 8, 561-570. \\ doi:10.3762/bjnano.8.60 \\ Received: 25 November 2016 \\ Accepted: 10 February 2017 \\ Published: 06 March 2017 \\ Associate Editor: J. J. Schneider \\ (C) 2017 Petukhov et al.; licensee Beilstein-Institut. \\ License and terms: see end of document.
}

\begin{abstract}
A study on the chemical stability of anodic alumina membranes and their performance in long-term water and organic solvent permeation experiments is reported. Anodic alumina possesses high stability for both protonic and aprotonic organic solvents. However, serious degradation of the membrane occurs in pure water, leading to a drastic decrease of permeance (over $20 \%$ of the initial value after the passing of $0.250 \mathrm{~m}^{3} / \mathrm{m}^{2}$ of pure water). The drying of the membrane induces further permeance drop-off. The rate of membrane degradation strongly depends on the $\mathrm{pH}$ of the penetrant solution and increases in basic media. According to ${ }^{27} \mathrm{Al}$ NMR and thermogravimetry results, the degradation of the membranes is associated with the dissolution of water-soluble $\left[\mathrm{Al}_{13} \mathrm{O}_{4}(\mathrm{OH})_{24}\left(\mathrm{H}_{2} \mathrm{O}\right)_{12}\right]^{7+}$ polyhydroxocomplexes and their further redeposition in the form of $\left[\mathrm{Al}(\mathrm{OH})_{4}\right]^{-}$, resulting in channels blocking. This process intensifies in basic $\mathrm{pH}$ due to the high positive charge of the anodic alumina surface. An approach for improving anodic aluminum oxide stability towards dissolution in water by carbon CVD coating of the membrane walls is suggested.
\end{abstract}

\section{Introduction}

Porous anodic aluminum oxide (AAO), developed as a protective coating, has received close attention of the membrane community due to its unusual porous structure represented by piercing cylindrical channels and exceptional transport characteristics. A very narrow pore size distribution, low pore tortuosity and controllable membrane porosity make AAO one of the top performers given its permeability/pore diameter ratio [1]. The synthetic procedure of AAO membranes enables signifi- cant tunability of the various porosity parameters (channel diameter 5-400 nm, interpore distance $20-600 \mathrm{~nm}$, porosity $10-50 \%$, thickness from $500 \mathrm{~nm}$ to $300 \mu \mathrm{m}$ ) [2-4]. It also allows membranes with a hierarchical porous structure to be obtained, where a supporting macroporous layer (aimed to provide mechanical durability) merges into the microporous selective skin layer [5]. All these issues make AAO extremely attractive for baromembrane processes, including micro- and ultrafiltra- 
tion, pervaporation, emulsification and membrane catalysis. AAO membranes are abundantly used as solid porous supports for asymmetric gas separation membranes [6,7] and have been tested in industrial applications as porous condensing layers for on-site associated gas conditioning [8,9]. However, most of AAO membrane functions are associated with gas separation processes [3,5,7,8,10-12], while only few reports can be found for liquid media [1,13-15]. In contrast, the narrow pore size distribution of anodic alumina membranes should result in a sharp cut-off curve and excellent filtration characteristics [1]. The possible reason for low publishing and application activity in the field is the degradation of AAO membrane materials, resulting in a substantial decrease of the solvent flux through the membrane with time [15].

Therefore, in the present study, we focused on the chemical stability of the membrane and the stability of the membrane performance towards water and organic solvents, as well as analysis of the AAO microstructure during degradation of the membranes. Several pathways for improving the AAO stability and performance are suggested.

\section{Results and Discussions}

The permeation of liquids through freshly prepared AAO membranes agrees well with Darcy's law: liquid flux linearly depends on transmembrane pressure (Figure 1a) and the slope of the curve is inversely proportional to the viscosity of the media (Figure 1b). In concert with a quadratic increase of the permeance with increasing membrane pore diameter (Figure 1b), it clearly reveals a Poiseuille flow mechanism for liquid transfer through AAO nanochannels. Notably, the water permeability of a $100 \mu \mathrm{m}$ thick AAO membrane with a pore di- ameters of $170 \mathrm{~nm}$ attains $220 \mathrm{~L} /\left(\mathrm{m}^{2} \cdot\right.$ bar $\left.\cdot h\right)$, which substantially exceeds that of most porous filters having the pore same size and is nearly equal to the permeability of track-etched membranes [16].

However, pure water flux through the AAO membrane was found to decrease with time, indicating degradation of the membrane material, which persuaded us to conduct long-term permeability experiments. The long-term flux stability was studied for both protonic and aprotonic solvents with different viscosity. The dependence of membrane permeance for different solvents on a specific permeate volume (per unit area) is represented in Figure 2. The parameters of the experiments are also summarized in Table 1. It can be seen that the permeance

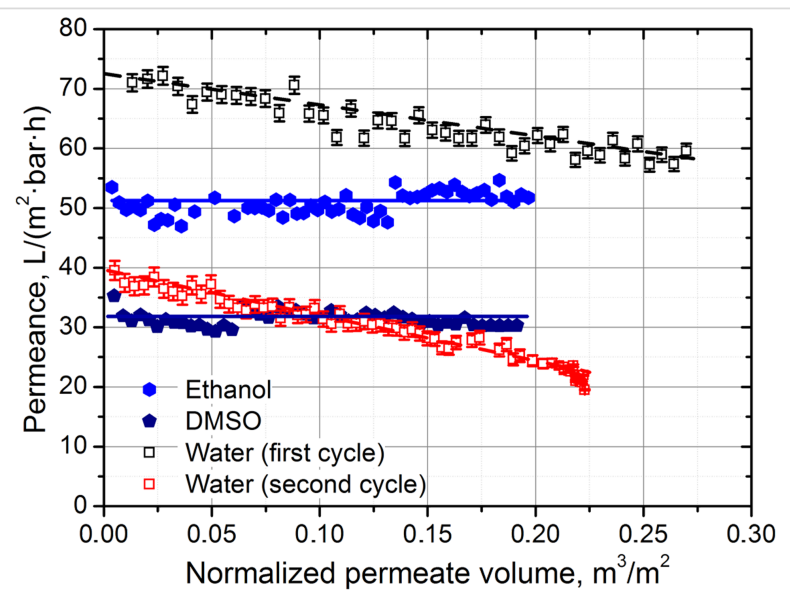

Figure 2: Dependence of the AAO_120V membrane $\left(D_{\text {pore }}=90 \mathrm{~nm}\right.$, $10 \%$ porosity, thickness $-100 \mu \mathrm{m}$ ) permeance for DMSO, ethanol and water on the specific permeate volume in long-term permeation experiments. (a)

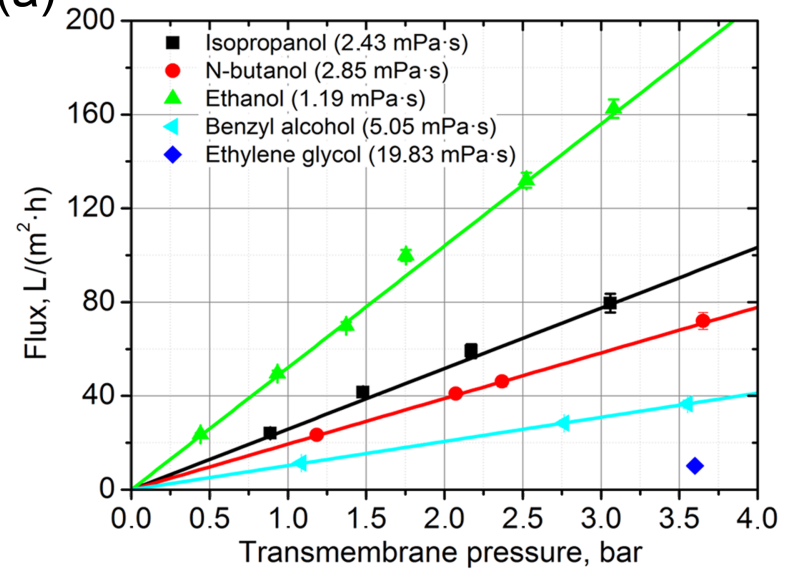

(b)

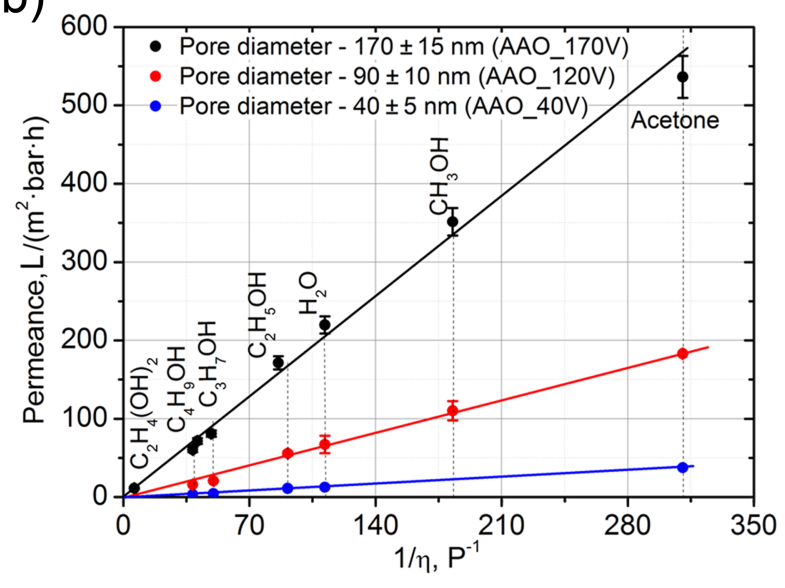

Figure 1: (a) Dependence of liquid flux vs transmembrane pressure for membrane AAO_120V with average pore diameter of $90 \pm 10 \mathrm{~nm}$ and thickness of $100 \mu \mathrm{m}$ and $(\mathrm{b})$ dependence of liquid permeance on the inverse viscosity of the liquid for $100 \mu \mathrm{m}$ membranes $\mathrm{AAO} \_40 \mathrm{~V}\left(D_{\text {pore }}=40 \mathrm{~nm} ; 10 \%\right.$ porosity), AAO_120V $\left(D_{\text {pore }}=90 \mathrm{~nm} ; 10 \%\right.$ porosity $)$ and $\mathrm{AAO} \_170 \mathrm{~V}\left(D_{\text {pore }}=170 \mathrm{~nm} ; 22 \%\right.$ porosity $)$. 
Table 1: Long-term permeation parameters for the AAO_120V membrane with an average pore diameter of $90 \pm 10 \mathrm{~nm}$, thickness $100 \mu \mathrm{m}$ and porosity $10 \%$.

\begin{tabular}{|c|c|c|c|c|c|c|}
\hline Solvent & $\begin{array}{l}\text { Viscosity, } \\
\mathrm{mPa} \cdot \mathrm{s}\end{array}$ & $\begin{array}{l}\text { Initial permeance, } \\
\mathrm{L} /\left(\mathrm{m}^{2} \cdot \text { bar } \cdot h\right)\end{array}$ & Solution $\mathrm{pH}$ & $\begin{array}{l}\text { Permeability } \\
\text { slope, } \text { bar }^{-1} \cdot \mathrm{h}^{-1}\end{array}$ & $\begin{array}{l}\text { Membrane } \\
\text { weight loss, \% }\end{array}$ & $\begin{array}{l}\text { Al concentration in } \\
\text { permeate, } \mathrm{mg} / \mathrm{L}\end{array}$ \\
\hline DMSO & 2.02 & $31.5 \pm 0.3$ & - & $-2.2 \pm 2.8$ & 0 & - \\
\hline \multirow[t]{4}{*}{ ethanol } & 1.19 & $49.0 \pm 0.5$ & - & $16.9 \pm 3.8$ & 0 & - \\
\hline & & & 3 & $20.5 \pm 2.2$ & 0.013 & 4.4 \\
\hline & & & 4.5 & $8.4 \pm 0.4$ & 0 & 2.8 \\
\hline & & & 6 (first cycle) & $-53.2 \pm 3.2$ & 0 & 0.04 \\
\hline \multirow[t]{4}{*}{ water } & 0.89 & $73 \pm 3$ & 6 (second cycle) & $-69.6 \pm 6.9$ & 0 & n.a. \\
\hline & & & 6.5 & $-366 \pm 16$ & 0 & 2.1 \\
\hline & & & 7.6 & $-800 \pm 30$ & 0 & 3.2 \\
\hline & & & 9 & $-1980 \pm 120$ & 0 & 6.7 \\
\hline
\end{tabular}

for both protonic and aprotonic organic solvents is quite stable during the long-term measurement, with small alterations explained by the slight temperature variation during experiments. In contrast, in the case of water filtration, the flux decreases substantially with an initial slope of $-53.2 \pm 3.2 \mathrm{bar}^{-1} \cdot \mathrm{h}^{-1}$. Moreover, a drastic decrease of the AAO membrane water permeance from $73 \pm 3 \mathrm{~L} /\left(\mathrm{m}^{2} \cdot\right.$ bar $\left.\cdot h\right)$ to $58 \pm 1 \mathrm{~L} /\left(\mathrm{m}^{2} \cdot\right.$ bar $\left.\cdot h\right)$ was observed after drying the membrane for $12 \mathrm{~h}$ at room temperature, followed by second-cycle measurements of water permeance. In the second cycle, the permeance also decreased with nearly the same slope (Figure 2, Table 1). The total permeance loss during two cycles ( $500 \mathrm{~L} / \mathrm{m}^{2}$ total throughput) equaled $72 \%$ of the initial value.

Notably, among a large number of studies concerning water permeance through AAO membranes [1,13-15], there has been only one reported case of the decrease of the liquid flux during filtration [15]. As only high purity distilled and deionized water was used in experiments, we suggested that the degradation of the membrane occurred by dissolution of the anodic aluminum oxide and its further redeposition on the pore walls. For a detailed determination of the anodic alumina degradation mechanism, chemical dissolution and buffered solution permeation experiments were performed for the AAO_120V membrane (Figure 3a,b). AAO membranes were found chemically stable over a wide $\mathrm{pH}$ range (3-9) with a mass loss during two hours with solvent immersion below the accuracy limit $(0.01 \%$, Table 1). The obtained stability range slightly exceeds the values reported by Mardilovich et al. ( $\mathrm{pH}$ 5.0-8.2) for the membranes obtained by anodization at $40 \mathrm{~V}$ [17]. Alterations of the $\mathrm{pH}$ stability ranges might be explained by the difference in chemical composition of membranes obtained in "mild" and "hard" anodization conditions. The membranes obtained at high voltages are known to contain nearly the same quantity of absorbed anions, but a much lower amount of the absorbed water [18] (see also Supporting Information File 1, Figures S1, $\mathrm{S} 2$ and Table 2). The greatest differences in chemical composition are presumed to localize in the outer anodic oxide layer [4].
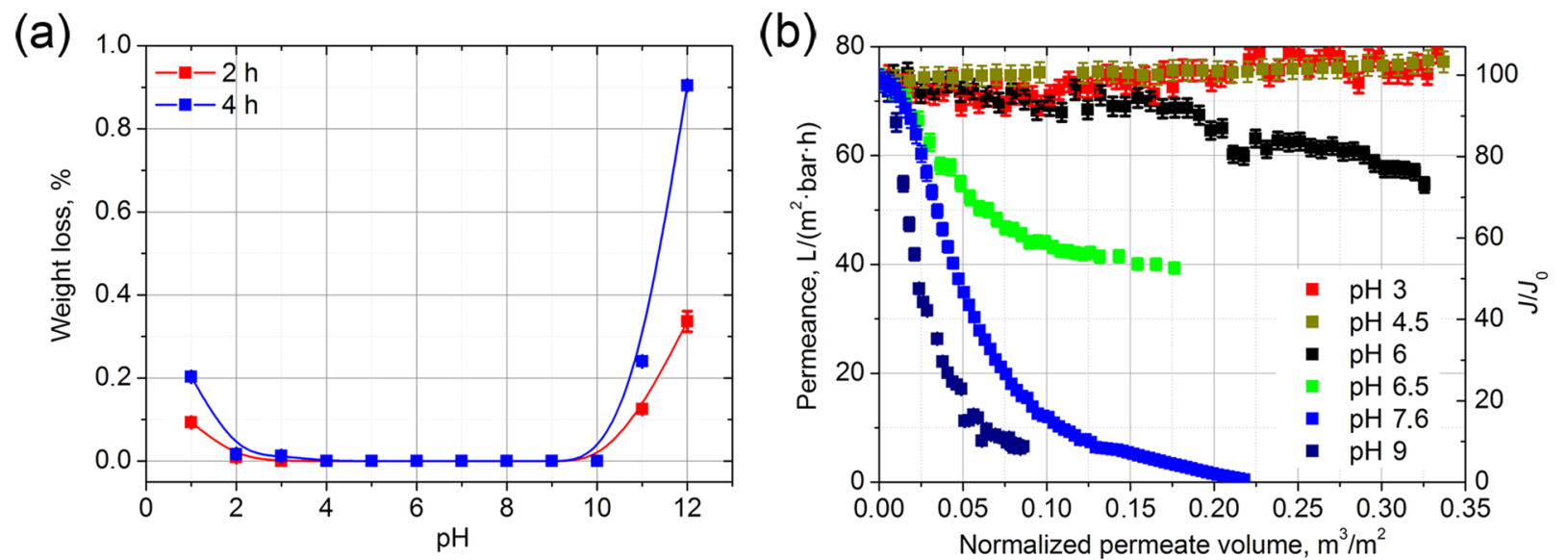

Figure 3: (a) Chemical dissolution of $\mathrm{AAO}$ at different $\mathrm{pH}$ and (b) dependence of $\mathrm{AAO}$ membrane permeance with $\mathrm{pH}$ during flow of buffered solutions. 
Table 2: Results of fitting the ${ }^{27}$ AI NMR spectra for membranes obtained in mild (AAO_40V) and hard (AAO_120V) anodization conditions in the initial state (i) and after pure water filtration (w).

\begin{tabular}{|c|c|c|c|c|c|c|c|c|}
\hline \multirow[t]{2}{*}{ Sample } & \multirow{2}{*}{$\begin{array}{l}\text { Pore } \\
\text { diameter, } \\
\mathrm{nm}\end{array}$} & \multirow{2}{*}{$\begin{array}{l}\text { Water } \\
\text { permeance } \\
\mathrm{L} /\left(\mathrm{m}^{2} \cdot \text { bar } \cdot h\right)\end{array}$} & \multicolumn{4}{|c|}{ Peak area, \% } & \multirow{2}{*}{$\begin{array}{l}\text { Water loss } \\
\text { below } 500^{\circ} \mathrm{C} \text {, } \\
\%\end{array}$} & \multirow{2}{*}{$\begin{array}{l}\mathrm{CO}_{2} \text { loss at } \\
\text { crystallization, } \\
\%\end{array}$} \\
\hline & & & $\begin{array}{l}\mathrm{Al}(4) \\
(\approx 60 \mathrm{ppm})\end{array}$ & $\begin{array}{l}\mathrm{Al}(5) \\
(\approx 35 \mathrm{ppm})\end{array}$ & $\begin{array}{l}\mathrm{Al}(6) \\
(\approx 0 \mathrm{ppm})\end{array}$ & $\begin{array}{l}\mathrm{Al}(6), \\
(\approx 7 \mathrm{ppm})\end{array}$ & & \\
\hline AAO_40V_i & \multirow{2}{*}{$40 \pm 5$} & $12.4 \pm 0.5$ & $19.5 \pm 0.1$ & $50.0 \pm 0.2$ & $27.1 \pm 0.1$ & $3.4 \pm 0.1$ & 3.7 & 5.3 \\
\hline AAO_40V_w & & $7.0 \pm 0.4$ & $20.1 \pm 0.1$ & $51.8 \pm 0.2$ & $28.1 \pm 0.1$ & - & 4.3 & 6 \\
\hline AAO_120V_i & \multirow{2}{*}{$90 \pm 10$} & $73 \pm 3$ & \multirow{2}{*}{$17.1 \pm 0.3$} & \multirow{2}{*}{$53.0 \pm 0.6$} & \multirow{2}{*}{$29.9 \pm 0.5$} & $0.5 \pm 0.1$ & 0.3 & 6 \\
\hline AAO_120V_w & & $46 \pm 1$ & & & & - & 1.2 & 6.3 \\
\hline
\end{tabular}

Contrary to the dissolution tests, the buffered solution permeation experiments indicated significant changes in permeance during long-term experiments within the chemical stability window. In case of the permeation of the solution with $\mathrm{pH} 3$ and 4.5 , a slight increase of the permeance was observed, indicating a partial dissolution of the membrane with an increase of the effective pore diameter. This was proved by the presence of 4.4 and $2.8 \mathrm{mg} / \mathrm{L}$ of $\mathrm{Al}^{3+}$ ions in permeate that for a buffer solution of $\mathrm{pH} 3$ and 4.5, respectively (Table 1). For solutions with neutral and basic $\mathrm{pH}$, a decrease of the permeance occurred. The permeate solution also contained dissolved aluminum (Table 1).

Alumina dissolution from the pore walls was also proved by ${ }^{27} \mathrm{Al}$ solid state NMR spectroscopy of initial membranes and membranes after $500 \mathrm{~L} / \mathrm{m}^{2}$ pure water filtration. The spectra for initial membrane $\mathrm{AAO}_{-} 40 \mathrm{~V}$ was obtained by mild anodization and this membrane after water filtration illustrates very close profiles with the only difference represented by a peak at $\approx 7$ ppm (Figure 4). The difference spectrum (Figure $4 \mathrm{~b}$ ) is fitted well by a single component with an asymmetric resonance signal shape centered at $7.5 \mathrm{ppm}$. The remaining alumina signals for both the initial membrane and that after water filtration are fitted well by the combination of the asymmetric resonance signals of tetra-, penta- and hexa-coordinated alumina, assuming the same half-widths and asymmetry parameters for different atoms. The fitting results are represented in Table 2.

Notably, the width of an additional component persistent in the initial membrane is much lower as compared to other components in the spectrum (Figure 4), which indicates much higher mobility for this atom. This peak corresponds well to octahedrally coordinated aluminum in polymerized $\left[\mathrm{Al}_{13} \mathrm{O}_{4}(\mathrm{OH})_{24}\left(\mathrm{H}_{2} \mathrm{O}\right)_{12}\right]^{7+}$ polyhydroxocomplexes or alumina atoms partially coordinated by $\mathrm{C}_{2} \mathrm{O}_{4}{ }^{2-}$ [19]. The first hypothesis seems more plausible based on thermogravimetry results

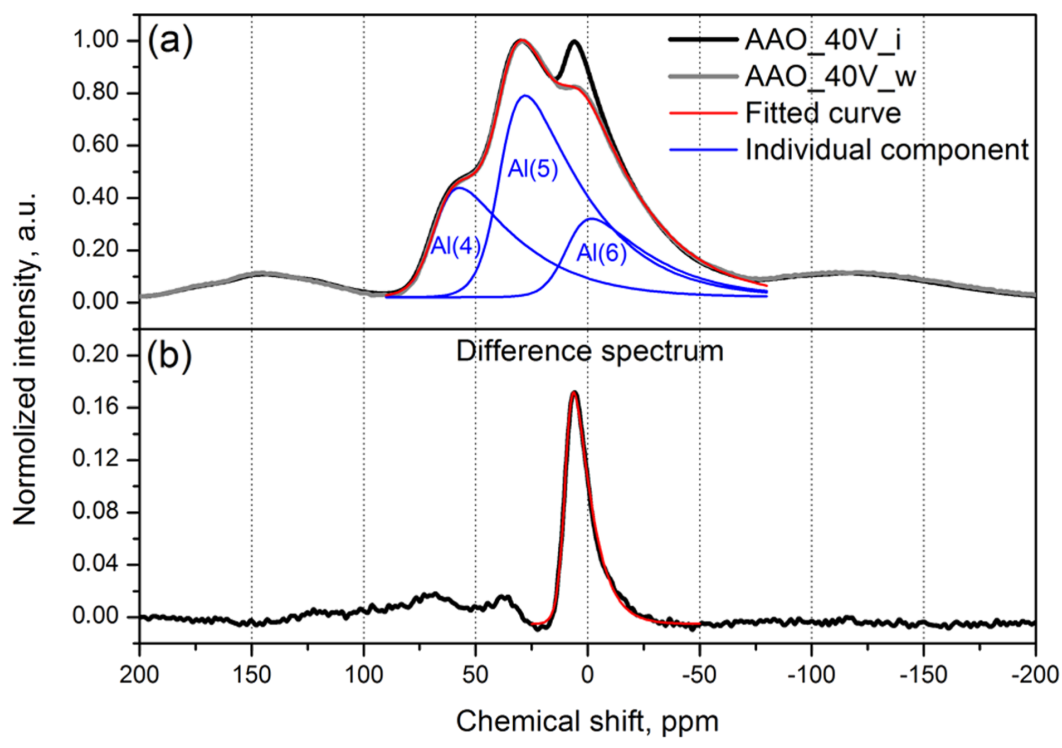

Figure 4: ${ }^{27} \mathrm{Al}$ solid-state NMR spectra of the initial membrane with pore diameter $40 \pm 5 \mathrm{~nm}$ (AAO_40V_i) and the same membrane after $500 \mathrm{~L} / \mathrm{m}^{2}$ pure water filtration (AAO_40V_w) (a) and the difference spectrum (b). 
presented in Supporting Information File 1 (Figure S1). The intensity of the additional component in the NMR spectra is much lower in the case of the AAO_120V membrane (pore diameter $90 \pm 10 \mathrm{~nm}$ ) obtained by hard anodization, which corresponds with the quantity of weakly bounded water (see Supporting Information File 1, Figure S1). Thus ${ }^{27} \mathrm{Al}$ NMR indicates the removal of aluminum atoms partially coordinated by oxalic acid or water-soluble aluminum polyhydroxocomplexes during water filtration experiments. This also suggests the initial location of those complexes at the surface of the outer anodic oxide layer. Despite the fact that several papers report on the formation of an AAO structure by coagulation of colloid alumina species [20,21], our results can unlikely be used as proof for the suggested mechanism because alumina polycation formation $\mathrm{pH}$ $(\approx 5)$ strongly changes the $\mathrm{pH}$ of the electrolyte used during anodization $(\approx 1)$.

However, dissolution of the membrane material does not explain the loss of membrane permeability in the long-term permeation experiments. On the other hand, since the polycondensation reaction for alumina hydroxocomplexes deposited on AAO walls can be reversible before oxolation takes place, both dissolution and deposition processes appear all over the film thickness. The efficiency of both reactions is dictated by the equilibrium constants. While at the entrance of the membrane equilibrium is strongly shifted to the dissolution of the alumina containing species, at the exit of the membrane, both dissolution and deposition reactions have the same rates. This leads to an effective transport of water-soluble alumina species to the permeate side of membrane during water filtration, encouraging possible blockage of channels. The effect is strongly enhanced by a slight gradient of $\mathrm{pH}$ within the pore due to the neutralization reaction by dissolved aluminium oxide.

The physical blockage of AAO nanochannels is well observed by scanning electron microscopy from cross sections of alumina membranes used in the permeability experiments with $\mathrm{pH} 9$ buffered solution (Figure 5). Small necks were found to block the majority of the pores. Moreover, the chemical composition of the blocking material was noted to be the same as that of the pore walls. This explains the mechanism of the degradation of the membranes by dissolution of aluminum-containing species from the pore walls and its further redeposition.

According to our model, the difference in the long-term permeability behavior of AAO membranes in acidic and basic media can obviously be attributed to the nature of the dissolved aluminum-containing species and their interactions with pore walls. Depending on the $\mathrm{pH}$ of the penetrating solution, one can assign a set of dissolution reactions for anodic alumina (Figure 6 [22]).

In an acidic or slightly acidic medium, the degradation involves dissolution of AAO with the formation of positively charged hydroxylated $\left[\mathrm{Al}(\mathrm{HO})\left(\mathrm{H}_{2} \mathrm{O}\right)_{3 . .5}\right]^{2+}$ and $\left[\mathrm{Al}(\mathrm{HO})_{2}\left(\mathrm{H}_{2} \mathrm{O}\right)_{2 . .4}\right]^{+}$ alumina species which further can condense in polynucleic hydroxocomplexes.

These complexes are repelled from the AAO membrane surface, having an isoelectric point at $\mathrm{pH} 8.0$ [23]. The charge of hydroxocomplexes that is dominant in water solution changes at $\mathrm{pH} \approx 6$. Taking into account a positive charge of the AAO surface at neutral $\mathrm{pH}$ values, this probably occurs in a solvent volume within the pore via hydrolysis reactions:

$$
\begin{aligned}
{\left[\mathrm{Al}(\mathrm{OH})_{2}\left(\mathrm{H}_{2} \mathrm{O}\right)_{4}\right]^{+}+\mathrm{OH}^{-} \longleftrightarrow \mathrm{Al}(\mathrm{OH})_{3}+4 \mathrm{H}_{2} \mathrm{O} \longleftrightarrow } \\
{\left[\mathrm{Al}(\mathrm{OH})_{4}\right]^{-}+\mathrm{H}^{*}+3 \mathrm{H}_{2} \mathrm{O} }
\end{aligned}
$$

Despite the fact that $\mathrm{Al}(\mathrm{OH})_{3}$ can block the channels itself, this process can unlikely be considered favourable, especially at basic $\mathrm{pH}$ values, as an unbound aluminium hydroxide would be dissolved much more easily than the alumina of the pore walls.
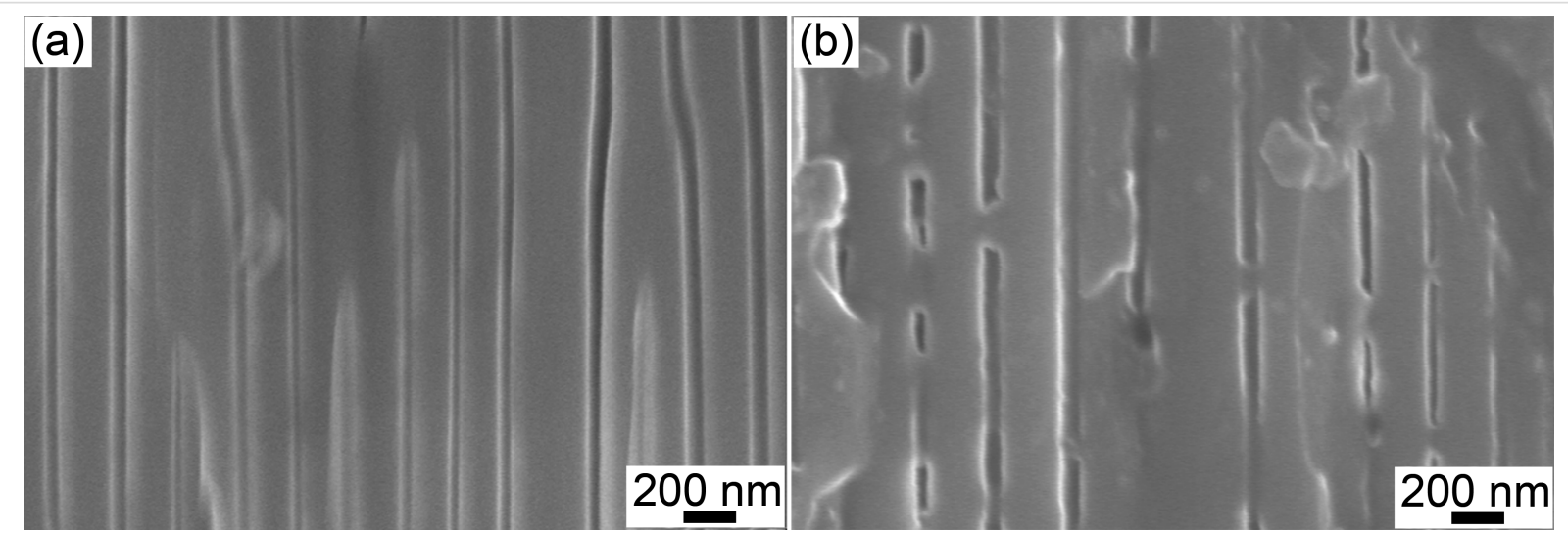

Figure 5: Scanning electron micrograph of the AAO_120V membrane cross section before (a) and after the filtration experiment (b). 


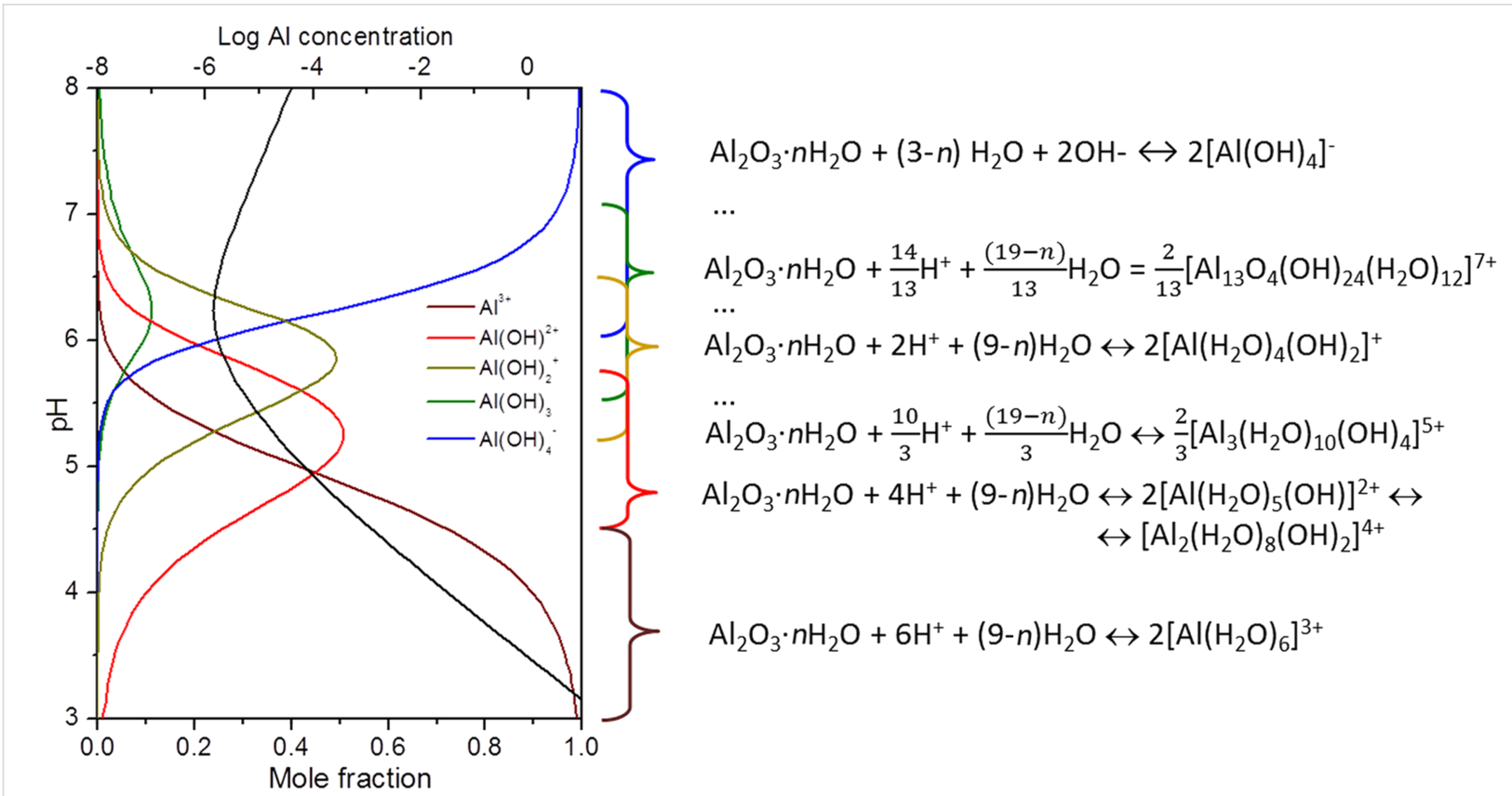

Figure 6: Concentration of the different aluminum complexes in solution depending on the $\mathrm{pH}$ of the media and dissolution reactions at different $\mathrm{pH}$.

The condensation of the hydrolysis products fits with the experimental results much better, especially since negatively charged $\left[\mathrm{Al}(\mathrm{OH})_{4}\right]^{-}$would readily be attracted by the AAO surface. As $\left[\mathrm{Al}(\mathrm{OH})_{4}\right]^{-}$species can be detected in water solution in noticeable amounts starting from $\mathrm{pH} 5$, the following reactions should be considered dominant for alumina redeposition leading to pore blocking in the $\mathrm{pH}$ range of 5-9 (Scheme 1). The condensation can also occur at Bronsted acid sites (Scheme 2).

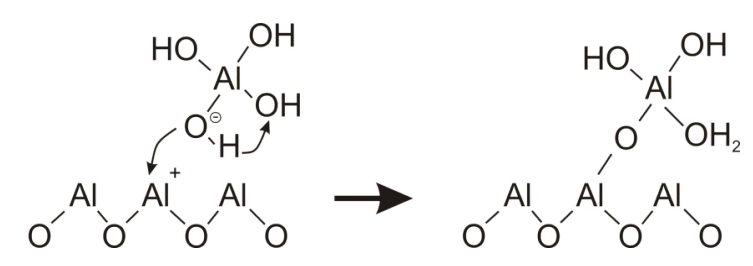

Scheme 1: Polycondensation reaction.

Higher $\mathrm{pH}$ values lead to further dissolution of the AAO membrane (Figure $3 \mathrm{~b}$ ). Thus, the permeation of water solutions depends strongly on the $\mathrm{pH}$ of the medium. In acidic water solutions, the dissolution of alumina walls takes place; no redeposition of dissolved species occurs due to the high positive charge of the AAO surface. In the neutral $\mathrm{pH}$ range, below the isoelectric point of the AAO membrane, the further redeposition of dissolved $\left[\mathrm{Al}(\mathrm{OH})_{4}\right]^{-}$ensues in nanochannels. Moreover, as the efficiency of $\left[\mathrm{Al}(\mathrm{OH})_{4}\right]^{-}$generation in the solution grows exponentially with $\mathrm{pH}$, the pore blockage rate also rapidly increases. At values greater than the isoelectric point, the redeposition efficiency decreases with increasing AAO negative charge; however, high $\mathrm{pH}$ values lead to the dissolution of the AAO material.

To avoid the permeability loss of anodic alumina in water solutions, and to take advantage of AAO membrane applications in aqueous medium, one needs to suppress the dissolution efficiency. The most convenient way involves oxolation and partial crystallization of hydroxides to crystalline alumina phases having extremely low solubility products. Unfortunately, thermal treatment of anodic alumina films is known to be accompa-

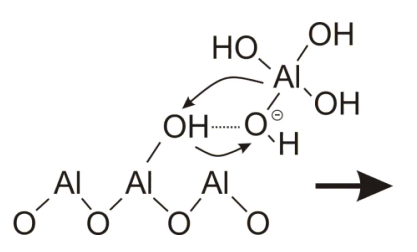<smiles>O[Al]O[Al](O[Al])O[Al](O)(O)O</smiles><smiles>CC1(c2ccccc2)CC1</smiles><smiles>O[Al]O[Al](O[Al])O[Al](O)(O)O</smiles> 
nied by increasing brittleness and possible membrane curling $[24,25]$. However, none of the pure chemical methods (phosphate or chromate treatment) results in the necessary stability improvement towards dissolution. Therefore, we have tested the long-term water permeation stability of thermally treated AAO membranes. The temperature of $600{ }^{\circ} \mathrm{C}$ was chosen to induce the crystallization of AAO and to avoid permeance loss due to destruction of the porous structure. However, thermally treated membranes have also illustrated water permeation loss during the operation and after membrane drying between the cycles. To provide an additional protection, carbon CVD (by the pyrolysis of hydrocarbons) was also adopted in the same thermal treatment regime to provide a continuous $10 \mathrm{~nm}$ thick coating of the internal porous oxide surface (Figure 7). The details on the coating procedure and analysis of the composite membranes are given in Supporting Information File 1.
The long-term permeability studies were carried out for pure AAO_120V and composite AAO_120V membranes modified with carbon coating (Figure 8). A slight decrease of the ethanol permeance from $49.4 \pm 2.1$ to $41.9 \pm 0.5 \mathrm{~L} /\left(\mathrm{m}^{2} \cdot\right.$ bar $\left.\cdot h\right)$ was observed for the composite membrane. In comparison with earlier published studies [26,27], we have not observed any improvement of the membrane performance due to slip flow. This can arise either from a decrease of the nanochannel diameter or from an insufficient smoothness of the carbon coating. In water permeation experiments, both the membranes illustrate a significant increase in membrane stability. Moreover, in both cases, the membrane permeance remains nearly the same after drying and the second utilization for water permeation. Only trace aluminum content was detected in permeate solutions. Despite this, we are unable to provide a quantitative comparison of long-term membrane performance for these two kinds of membranes as (a)

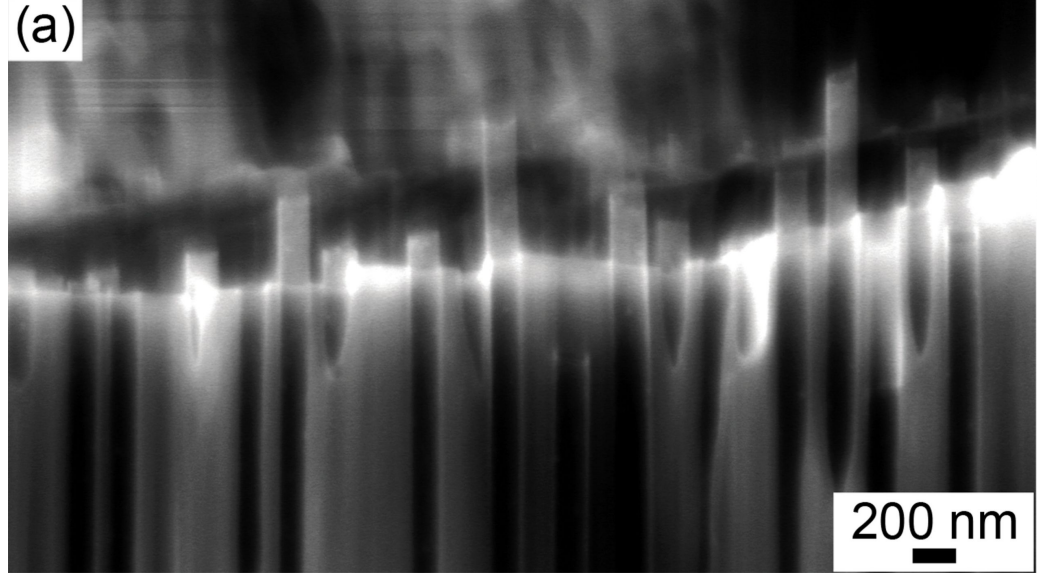

(b)

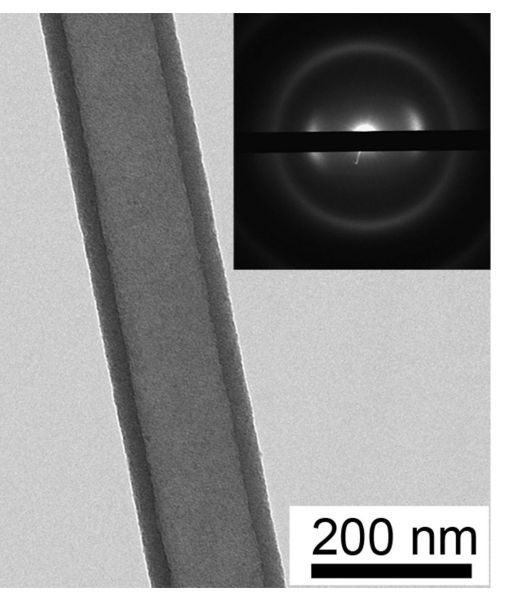

Figure 7: SEM (a) and TEM (b) micrographs of carbon nanotubes formed in anodic alumina membrane pores by CVD.
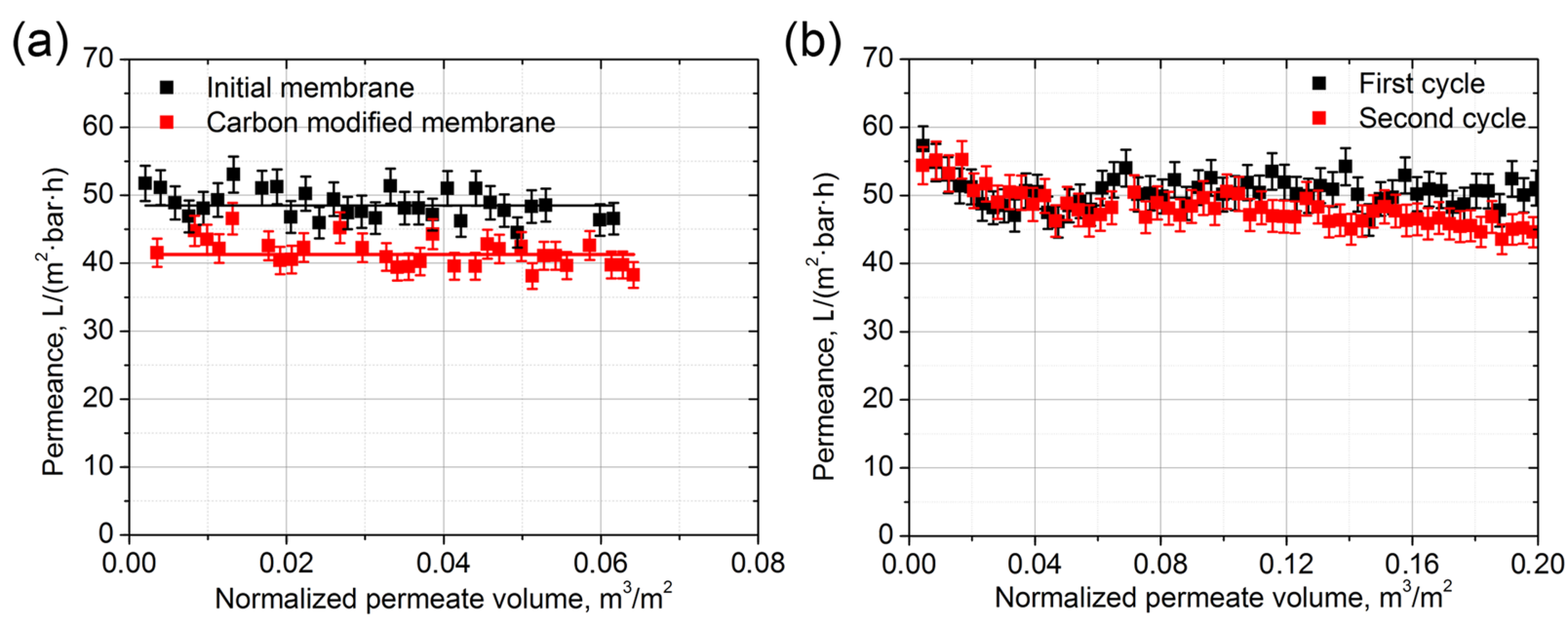

Figure 8: Comparison of ethanol permeance for initial membrane and the membrane modified with carbon (a) and the water permeance of the CVDmodified membrane (b). 
their permeability losses fall within measurement error limits; however, slightly better stability of carbon-coated membranes was noticed. Therefore, both the thermal treatment procedure and the CVD coating of the membrane with an amorphous carbon results in the stabilization of AAO membranes towards dissolution in water. This therefore allows for further utilization of AAO for baromembrane processing.

\section{Conclusion}

In this study, the chemical stability of AAO membranes and the stability of the membrane performance towards water and organic solvents were reported. As-prepared anodic alumina membranes were found to possess high stability to both protonic and aprotonic organic solvents. However, significant degradation of the membrane performance was observed for water solutions due to dissolution of polymerized $\left[\mathrm{Al}_{13} \mathrm{O}_{4}(\mathrm{OH})_{24}\left(\mathrm{H}_{2} \mathrm{O}\right)_{12}\right]^{7+}$ polyhydroxocomplexes. This effect results in strong variations in the AAO membrane performance depending on the $\mathrm{pH}$ of the penetrant solution. In acidic or slightly acidic media, the dissolution of alumina leads to a slight increase of the membrane permeance. No redeposition of the dissolved species occurs due to the high positive charge of the AAO surface. In the neutral $\mathrm{pH}$ range, below the isoelectric point of the AAO membrane, further redeposition of dissolved $\left[\mathrm{Al}(\mathrm{OH})_{4}\right]^{-}$ensues in the nanochannels. Moreover, as the efficiency of $\left[\mathrm{Al}(\mathrm{OH})_{4}\right]^{-}$generation in the solution grows exponentially with $\mathrm{pH}$, the pore blockage rate also rapidly increases. Beyond the isoelectric point, the redeposition efficiency decreases with increasing AAO negative charge; however, high $\mathrm{pH}$ values also lead to the dissolution of the AAO material. An approach for improving the AAO stability towards the dissolution in water by carbon CVD coating of the membrane walls was suggested. This method resulted in the stabilization of the AAO membranes, which could allow for the further utilization AAO for baromembrane processes.

\section{Experimental \\ Sample preparation}

Prior to anodization, aluminum foil was annealed and electropolished according to procedure described elsewhere [28]. The anodization was carried out in a two-electrode cell. The electrolyte was pumped through the cell by a peristaltic pump, and its temperature was kept in the range of $0-2{ }^{\circ} \mathrm{C}$ during anodization. For the preparation of membranes with an average pore diameter of $40 \mathrm{~nm}$ and $90 \mathrm{~nm}$, aluminium was anodized in $0.3 \mathrm{M}$ $\mathrm{H}_{2} \mathrm{C}_{2} \mathrm{O}_{4}(98 \%$, Aldrich) under mild and hard anodization conditions at $40 \mathrm{~V}$ and $120 \mathrm{~V}$, respectively. A membrane with an average pore diameter of $170 \mathrm{~nm}$ was obtained by anodization in $0.1 \mathrm{M} \mathrm{H}_{3} \mathrm{PO}_{4}$ at $170 \mathrm{~V}$. In the case of mild anodization conditions $(40 \mathrm{~V})$, a two-step anodization procedure was used for improving the membrane permeance. The $100 \mu \mathrm{m}$ sacrificial layer formed by the first anodization was selectively removed in the solution containing $0.6 \mathrm{M} \mathrm{H}_{3} \mathrm{PO}_{4}+0.2 \mathrm{M} \mathrm{CrO}_{3}$ at $60{ }^{\circ} \mathrm{C}$. The second anodization was performed under the same conditions. In hard anodization conditions the voltage was increased to the target voltage of $120 \mathrm{~V}$ during the first step with a constant rate of $1 \mathrm{~V} \cdot \mathrm{s}^{-1}$ in order to avoid electrical breakdown of the oxide film on the first step. The thickness of the formed films was coulometrically controlled, resulting in $100 \mu \mathrm{m}$ thick membranes [28].

After anodization, the oxide films were separated from the metallic substrates by selective metal dissolution in $0.5 \mathrm{M}$ $\mathrm{CuCl}_{2}(5 \mathrm{vol} \% \mathrm{HCl})$. Subsequently, the pore bottoms were opened by chemical etching in $25 \mathrm{wt} \% \mathrm{H}_{3} \mathrm{PO}_{4}$ aqueous solution at $25{ }^{\circ} \mathrm{C}$ followed by electrochemical detection of the pore opening [28].

To increase on the first step membrane stability, high-temperature dehydration was carried out by an annealing at $600{ }^{\circ} \mathrm{C}$ $(2 \mathrm{~h})$. To prevent curling or breaking of membrane during heat treatment, the heating and cooling rates were set to $1{ }^{\circ} \mathrm{C} / \mathrm{min}$. A protective carbon layer was deposited onto anodic alumina pore walls by CVD from 15 vol $\% \mathrm{C}_{3} \mathrm{H}_{6}$ in $\mathrm{He}(150 \mathrm{~mL} / \mathrm{min})$ at $600{ }^{\circ} \mathrm{C}$ for two hours. The heating/cooling rates were also set to $1{ }^{\circ} \mathrm{C} / \mathrm{min}$.

\section{Sample characterization}

Scanning electron microscopy (SEM) images were recorded on a Supra 50VP instrument (LEO) instrument. The deposited carbon layer was examined by transmission electron microscopy (TEM) after dissolution of the alumina matrix using a Zeiss Libra 200 FX instrument. Raman spectroscopy studies were carried out on a Renishaw InVia spectrometer using $\mathrm{He}-\mathrm{Ne}$ laser excitation $(633 \mathrm{~nm}) .{ }^{27} \mathrm{Al}$ NMR spectra were recorded on a Bruker AVANCE II 400WB spectrometer at $104.3 \mathrm{MHz}$, using $0.7 \mathrm{~ms}\left(15^{\circ}\right)$ pulses and $0.5 \mathrm{~s}$ recycle delays with magicangle-spinning at $10 \mathrm{kHz}$. The chemical shifts of ${ }^{27} \mathrm{Al}$ are given in ppm from external $\mathrm{Al}\left(\mathrm{H}_{2} \mathrm{O}\right)_{6}{ }^{3+}$.

The liquid permeance measurements were performed using a dead-end Teflon cell at a temperature of $25 \pm 2{ }^{\circ} \mathrm{C}$. The permeability was calculated from the pressure difference measured by pressure transducers and the mass of accumulated permeate. The time step of the measurement was $5 \mathrm{~min}$. Before the experiment, all tested liquids and solutions were prefiltered through Chromafil Xtra $0.2 \mu \mathrm{m}$ filters. The chemical stability and buffer solution permeation experiments were performed using water solutions with different $\mathrm{pH}$. For preparation solutions with $\mathrm{pH}$ in range from 3 to 9, the buffers listed in Table 3 were used. The composition of the buffered solutions was optimized to minimize the ionic strength difference and diminish the influ- 
Table 3: Composition of buffer solutions used in permeation experiments and chemical stability measurements.

\begin{tabular}{|c|c|c|c|}
\hline \multirow{2}{*}{$\begin{array}{l}\mathrm{pH} \\
3\end{array}$} & \multirow{2}{*}{$\begin{array}{l}\text { Buffer type } \\
\text { acetate }\end{array}$} & \multicolumn{2}{|c|}{ Concentration } \\
\hline & & $0.139 \mathrm{M} \mathrm{CH}_{3} \mathrm{COOH}$ & $0.04 \mathrm{M} \mathrm{CH}_{3} \mathrm{COONa}$ \\
\hline 4.5 & & $0.065 \mathrm{M} \mathrm{CH}_{3} \mathrm{COOH}$ & $0.096 \mathrm{M} \mathrm{CH}_{3} \mathrm{COONa}$ \\
\hline 6 & - & $0.12 \mathrm{M} \mathrm{NaCl}$ & - \\
\hline 6.5 & phosphate & $0.026 \mathrm{M} \mathrm{KH}_{2} \mathrm{PO}_{4}$ & $0.033 \mathrm{M} \mathrm{Na}_{2} \mathrm{HPO}_{4}$ \\
\hline 7.6 & pinstiate & $0.007 \mathrm{M} \mathrm{KH}_{2} \mathrm{PO}_{4}$ & $0.044 \mathrm{M} \mathrm{Na}_{2} \mathrm{HPO}_{4}$ \\
\hline 9 & carbonate-bicarbonate & $0.09 \mathrm{M} \mathrm{NaHCO}_{3}$ & $0.01 \mathrm{M} \mathrm{Na}_{2} \mathrm{CO}_{3}$ \\
\hline
\end{tabular}

ence of the electrical double-layer thickness during permeation experiments.

\section{Supporting Information}

Supporting Information File 1 contains the thermal analysis data of membranes obtained under "hard" and "mild" anodization conditions, in addition to experimental details regarding the carbon coating and Raman spectrum of the obtained carbon coating.

\section{Supporting Information File 1}

Thermal analysis and membrane modification via CVD process.

[http://www.beilstein-journals.org/bjnano/content/ supplementary/2190-4286-8-60-S1.pdf]

\section{Acknowledgements}

The work is partially supported by the Russian Science Foundation Grant No. 17-13-01271 in part of membranes microstructure characterizations, Russian Foundation of Basic Research Grant No. 16-29-05285 and Lomonosov Moscow State University Development Programme. The activity of D.I. Petukhov is supported by an individual grant of Russian President MK-799.2017.3 and by an individual grant of the Russian Foundation for Basic Research No. 16-33-60195_mol_a_dk. We thank P.V. Evdokimov for help with the thermal analysis and I.A. Kasyanov for help with the NMR study of the anodic alumina membranes.

\section{References}

1. Lee, K. P.; Mattia, D. J. Membr. Sci. 2013, 435, 52-61. doi:10.1016/j.memsci.2013.01.051

2. Li, A. P.; Müller, F.; Birner, A.; Nielsch, K.; Gösele, U. J. Appl. Phys. 1998, 84, 6023-6026. doi:10.1063/1.368911

3. de L. Lira, H.; Paterson, R. J. Membr. Sci. 2002, 206, 375-387. doi:10.1016/S0376-7388(01)00782-7

4. Lee, W.; Park, S.-J. Chem. Rev. 2014, 114, 7487-7556. doi: $10.1021 /$ cr500002z
5. Petukhov, D. I.; Napolskii, K. S.; Eliseev, A. A. Nanotechnology 2012, 23, 335601. doi:10.1088/0957-4484/23/33/335601

6. Chernova, E.; Petukhov, D.; Boytsova, O.; Alentiev, A.; Budd, P.; Yampolskii, Y.; Eliseev, A. Sci. Rep. 2016, 6, 31183. doi:10.1038/srep31183

7. Inguanta, R.; Amodeo, M.; D'Agostino, F.; Volpe, M.; Piazza, S.; Sunseri, C. J. Electrochem. Soc. 2007, 154, D188-D194. doi:10.1149/1.2432067

8. Petukhov, D. I.; Surtaev, V. N.; Eliseev, A. A. Nauchno-technicheskiy vestnik OAO«NK «Rosneft» 2015, 41, 47-51.

9. Pyatkov, E. S.; Surtaev, V. N.; Petukhov, D. I.; Chernova, E. A.; Lukashin, A. V.; Solntsev, K. A.; Eliseev, A. A. Neftyanoe khozyaystvo - Oil Industry 2016, 5, 82-85.

10. Inada, T.; Uno, N.; Kato, T.; Iwamoto, Y. J. Mater. Res. 2005, 20, 114-120. doi:10.1557/JMR.2005.0016

11. Petukhov, D. I.; Eliseev, A. A. Nanotechnology 2016, 27, 085707. doi:10.1088/0957-4484/27/8/085707

12. Petukhov, D. I.; Berekchiian, M. V.; Pyatkov, E. S.; Solntsev, K. A.; Eliseev, A. A. J. Phys. Chem. C 2016, 120, 10982-10990. doi:10.1021/acs.jpcc.6b02971

13. Lee, K. P.; Leese, H.; Mattia, D. Nanoscale 2012, 4, 2621-2627. doi:10.1039/c2nr30098b

14. Lee, K. P.; Mattia, D. Ind. Eng. Chem. Res. 2013, 52, 14866-14874. doi:10.1021/ie401960n

15. Itaya, K.; Sugawara, S.; Arai, K.; Saito, S. J. Chem. Eng. Jpn. 1984, 17, 514-520. doi:10.1252/jcej.17.514

16. Mehta, A.; Zydney, A. L. J. Membr. Sci. 2005, 249, 245-249. doi:10.1016/j.memsci.2004.09.040

17. Mardilovich, P. P.; Govyadinov, A. N.; Mazurenko, N. I.; Paterson, R. J. Membr. Sci. 1995, 98, 143-155. doi:10.1016/0376-7388(94)00185-2

18. Lee, W.; Ji, R.; Gösele, U.; Nielsch, K. Nat. Mater. 2006, 5, 741-747. doi:10.1038/nmat1717

19. Masion, A.; Thomas, F.; Tchoubar, D.; Bottero, J. Y.; Tekely, P. Langmuir 1994, 10, 4353-4356. doi:10.1021/la00023a069

20. Michelson, C. E. J. Electrochem. Soc. 1968, 115, 213-219. doi:10.1149/1.2411088

21. Pashchanka, M.; Schneider, J. J. J. Mater. Chem. 2011, 21 , 18761-18767. doi:10.1039/c1jm13898g

22. Saukkoriipi, J. Theoretical study of the hydrolysis of aluminum complexes. Ph.D. Thesis, University of Oulu, Finland, 2010.

23. Winkler, B. H.; Baltus, R. E. J. Membr. Sci. 2003, 226, 75-84. doi:10.1016/j.memsci.2003.07.015

24. Wang, D. L.; Ruan, Y. F.; Zhang, L. C.; Zhu, W.; Wang, P. F. Cryst. Res. Technol. 2013, 48, 348-354. doi:10.1002/crat.201200328

25. Choudhari, K. S.; Sudheendra, P.; Udayashankar, N. K. J. Porous Mater. 2012, 19, 1053-1062. doi:10.1007/s10934-012-9568-z 
26. Whitby, M.; Cagnon, L.; Thanou, M.; Quirke, N. Nano Lett. 2008, 8, 2632-2637. doi:10.1021/n1080705f

27. Mattia, D.; Leese, H.; Lee, K. P. J. Membr. Sci. 2015, 475, 266-272. doi:10.1016/j.memsci.2014.10.035

28. Petukhov, D. I.; Napolskii, K. S.; Berekchiyan, M. V.; Lebedev, A. G.; Eliseev, A. A. ACS Appl. Mater. Interfaces 2013, 5, 7819-7824. doi:10.1021/am401585q

\section{License and Terms}

This is an Open Access article under the terms of the Creative Commons Attribution License

(http://creativecommons.org/licenses/by/4.0), which permits unrestricted use, distribution, and reproduction in any medium, provided the original work is properly cited.

The license is subject to the Beilstein Journal of

Nanotechnology terms and conditions:

(http://www.beilstein-journals.org/bjnano)

The definitive version of this article is the electronic one which can be found at: doi:10.3762/bjnano.8.60 